\title{
How to Cope with Risks --- Environmental Security Concept in the Modern Society
}

\author{
Meng Tang \\ School of Law, Changchun University of Science and Technology \\ Changchun 130022, China \\ E-mail: 13504324857@163.com \\ Xiuping Dong \\ School of Marxism, Changchun University of Science and Technology \\ Changchun 130022, China \\ E-mail: windyxiu@sina.com
}

\begin{abstract}
Received: July 7, $2011 \quad$ Accepted: July 25, $2011 \quad$ Published: October 1, 2011
doi:10.5539/ass.v7n10p249 URL: http://dx.doi.org/10.5539/ass.v7n10p249
\end{abstract}

\begin{abstract}
The largest feature of environmental issue in the current society is its unpredictability. Under such a circumstance, what does environmental security mean to human being? Security is not only evaluation on an objective fact, but more an outcome of people's subjective construction. TO focus on how people's subjective elements get involved in the environmental issue and on evaluation on the subjective elements after involvement is quite necessary to cope with risks and set up correct environmental security concept in the modern society.
\end{abstract}

Keywords: Environmental security, Trust, Introspection, Aggressiveness

\section{Meaning of environmental security}

According to Cai Shouqiu, the so-called environmental security refers to a kind of security condition in which the environment human beings depend on is not polluted and damaged. (Cai Shouqiu, 2001) In this definition, the precondition of environmental security is existence of an environmental issue and the environmental issue has become a formerly existing subjective fact and has been effectively resolved. According to the authors, this definition on environmental security is based on substantial existence of the environmental issue. However, this viewpoint exactly ignores or shields unpredictability of environmental issues. Environmental issues can generally be classified into two types, one type of issues caused by changes of the natural environment and the other type of issues caused by human activities. Natural disasters and environmental disruption caused by the natural environment bring influences and damages to human being can even sometimes cause fatal attack to people in a certain region, such as, volcanic eruption, earthquake, typhoon, tsunami, flood, drought, furacana and so on. Of course, ecological environmental disruption cases caused by human activities are also common occurrence. Anyway, there is a common feature both in environmental issues caused by changes of the natural environment and in environmental issues caused by human activities, namely, unpredictability. If the environmental issues are just as human beings catch a cold, then it is likely to take corresponding cure measures. However, if the environmental issues are as Aids which erode our body silently, then it is not likely to discover them and there is no way to resist them until the damage to our body is quite obvious, when it will be too difficult to cure them. Just as a test on a frog, when you put a frog into boiling water, the grog will struggle to jump and try to escape from the danger situation. On the contrary, if you put the frog into cold water and use a slow fire for stew, finally the frog may be cooked to death after it has shared a comfortable water temperate. Then, whether human being is the frog that "dies from peace and happiness"? When our survival environment is becoming continuously "hot", whether we will keep enough alertness to danger? How we take certain actions? All these problems involve the following two issues. One is understanding about connotation of environmental security and the other one is introspection on environmental security. 
In order to discuss environmental security, it is necessary to firstly come to understand what security is. When the author was asked whether he felt secure, then what his answer was based on? Whether he would be based on the fact that the environment he was in did not include any harmful influences of danger, threat or damage in terms of health? As a matter of fact, it is far from enough to make judgment merely at the level of substantial material. The author was not clear whether he would be secure when he took a taxi to go to the airport and whether he would be secure when he boarded the airplane. The reason why he could not make a correct judgment was that division of knowledge in the modern society is so developed, so nobody is able to be an expert in all professional fields. When the author took a taxi, "he totally entered an environment which was flooded with professional knowledge, including design and manufacturing of automobiles, highway, road junction, traffic signal and a lot of other related knowledge." "When the author boarded the airplane, he entered another expert system, and his own technical knowledge on this system merely remained at the most limited and primary stage". (Anthony Giddens, 2000, 24-25) Based on that, when the author answered whether he felt secure, there were actually so many elements that were controlling him. If he was put in an environment that was totally within his knowledge, the judgment he made on whether he felt secure was rational. Then, whether he could not make judgment on whether he felt secure when he was put in the environment of modern society which was flooded with expert system? If one can't not make sure whether he was secure, then he is unable to successfully go on with his daily life and what accompanies with that is fear of "Kierkegaard, namely, a situation submerged by anxiety." (Anthony Giddens, 1998, 41). If people are perplexed by this anxiety for a long time, then a "normal person" will regard this kind of anxiety as irrational. Nevertheless, it would be better to explain this kind of feeling as outcome of excessive sensitiveness of emotion than to explain this kind of feeling as irrational." (Anthony Giddens, 2000, 81-82). In the modern society, there are not many people who are completely aware whether they are secure, but why not anybody does not have the feeling of high insecurity? In dealing with daily living routines, it is unimaginable if one can't resort to a "protection crust" (Anthony Giddens, 1998, 44) to maintain a basic security sense. And we need to search for answers about this kind of protection crust from the perspective of psychology.

According to Erikson, there exists a kind of "basic trust" (Anthony Giddens, 2000, 82) in the process of early childhood growth. "What a baby gradually acquire is its dependence on and care for the one who nurture it. In the meanwhile, the baby has learned that it has to propose its demands in the way that the one who nurtures it requires, and it also knows that the caregiver also expects for dependability and trust in behaviors of his child." Anthony Giddens, 2000, 84) At the same time, there also exists a kind of absence between the baby and the caregiver. This kind of absence means that the baby stands absence of its caregiver in terms of time and space. Absence is quite critical for integration of trust of the baby and the ability to meet an emergency in the society. At the beginning when the trust is formed, there is a basic characteristics, namely, the baby is quite sure that the caregiver will go back to it. Thus, the trust eliminates any distance in terms of time and space, and so it avoids any existential anxiety. (Anthony Giddens,2000, 84-85) Therefore, works of Erikson brings us to two significant concepts. Firstly, the basic trust between presence and caregivers is established in an individual at his early childhood; secondly, an individual can endure absence of the caregivers at the early childhood, and the reason for his endurance is that the basic trust eliminates distance in terms of time and space. Trust in people when they are present is totally understandable which is established on judgment of people's honesty. However, trust in an expert system is relatively complicated, which requires us to have profound understanding in absence. If we are able to prove that the expert system is actually a kind of mechanism of absence, then our trust in the expert system is also understandable.

The reason for birth of the concept of absence is, as a matter of fact, originated from understanding of Britain Sociologist Anthony Giddens in separation of time and space in the modern society. Giddens made a comparison between different understandings of pre-modern culture and post-modern culture in relationship between time and space. According to the pre-modern culture, time and space are connected together, in which "when" is almost always connected with "where" and the connection is always inaccurate and instable. Emergence of the mechanical block has decisive significance for time to separate from space. The block reflects a kind of "virtual" time. If we calculated according to this method, we can accurately unify consistence of time and consistence of time in a social organization, which is symbolized by standardization of the calendar within a global scope. "Virtuality of time", to a great extent, is the precondition for "virtuality of space" and unification of time is the foundation to control space. We can come to comprehend development of "virtual space" from the perspective of separation of space and place. Place and occasion are closely connected together, which refers to distribution of material environment for social activities in terms of geography. In the pre-modern society, space and place are always consistent. In most cases, the spatial dimension for social life is under control of "presence", namely, territoriality activities. However, in the modernity condition, formation of all sorts of other elements for 
"absence" gradually separate space from place, which is no longer the kind of face-to-face interactive situation as in the pre-modern culture. The present face-to-face interactive situation is determined by social influences and social relations that are distant from the occasion. (Anthony Giddens, 2000, 15-17) Of course, separation of time and space has not reached the acme of perfection, since it is also dialectical and bi-directional. On one hand, separation of time and space gives rise to alienation of people who are present. On the other hand, separation of time and space closely brings globalization and locality together. For instance, if I am having a conversation with one who in on the other side of the earth, the most those who are in the same house may ask is "Where is she" and "What is she doing".

Presence and absence caused by separation of time and space enables social relations to "break away" from "interactive territoriality relevance and from the relevance that is reconstructed through infinite traversing of uncertain time". (Anthony Giddens, 2000, 18) This phenomenon is termed by Giddens as "disembedding". Giddens made a distinction between the two types of disembedding mechanisms. The first type was called formation of symbolic signs and the second was called establishment of an expert system. The so-called symbolic signs refer to media of interactive communication, which can transmit information, without taking into consideration particular features of the individuals or groups who deal with the information in a particular occasion, such as, symbols symbolizing political legality, and currency symbols, etc. The so-called expert system refers to a system constituted by technical achievements and professional teams, which waives the vast scope of the material and social environment in which we live. (Anthony Giddens, 2000, 18-24) "Expert system is also a kind of disembedding mechanism, since it directly separates the social relations from a specific context". (Anthony Giddens, 2000, 25) In such way, a kind of absence is formed. When we deal with daily living routines in the modern society that is constituted by expert systems, it is the absent expert systems that offer a kind of "anticipated guarantee" through a long distance relationship. (Anthony Giddens, 2000, 25) "Trust in the expert systems neither depends on total participation in these processes, nor depends on proficiency in knowledge mastered by those experts." (Anthony Giddens, 2000, 25) As a matter of fact, it is unlikely to realize that. Trust in the expert systems, to a large extent, originates from tolerance of early childhood in absence of the caregivers proposed by Erikson. However, the reason why non-professional people have trust in expert systems is, to a large extent, is due to anticipation offered by the expert systems and reliability of the results.

Of course, trust in expert systems does not only refer to basic trust that has been formed in early childhood, but also originates from the following two elements. On one hand, the socialization process of human being cultivates respect towards technical knowledge and cultivates more general social attitudes, which predicts respect towards all technical knowledge. In the system of modern education, education which imparts science is also placed as the "first principle". In the principle, knowledge is deemed as incontrovertible. Thus, science has always maintained its image as dependable knowledge, and this kind of knowledge breeds an attitude of respecting all professional technology. (Anthony Giddens, 2000, 77-78) On the other hand, in the modernity situation, expert system is all-pervasive and penetrates into all aspects of social life. (Anthony Giddens, 1998, 20) It is difficult for human beings to break away from control of expert system on our daily life. Of course, people can also take an attitude of resisting all abstract systems, but that always seems extreme.

It can be discovered from the above that, authors of this article believe that the problem whether one feels secure in the modern society will necessarily involve elements of trust. And understanding of security always contains elements of trust in both trust in human being and trust in an abstract system.

\section{Introspection on environmental security}

Introspection on environmental security should still start from introspection on security. Then, why we have to make introspections? What we introspect on? These are two precondition issues. Giddens pointed out, "The reason why human society is different from animal society is that human society is a practical activity that is established on the basis of reflexivity". (Anthony Giddens, 1998, 308) in this sense, we can think that the basic existence means of human being is introspection. History of human society is a developmental history of "introspection". (Xiao Ying, 2004) In the definition of security, we can find that trust in the abstract system, especially trust in expert system, is the critical factor to generate an intimate conviction without no harm. We would rather say it is a trust in the professional knowledge applied by experts than say it is a trust in the expert system. After socialization of human being, respect towards professional knowledge has been cultivated among people. Ever since the Enlightenment, it is generally believed that the natural science belongs to a type of necessity knowledge and has definiteness. The reason why people make such as judgment has something to do with thriving of the enlightenment reason. Ever since Descartes, a well-known rationalist and enlightenment thinker, started the enlightenment reason of "I think, there I am", rationalism has become the core of western civilization. This kind of rationalism believes that, human being has the capacity of reason and they can build an 
ideal modern society by the power of reason. This thought, without doubt, has been powerfully pushed forward by the scientific progress since the Enlightenment and the enormous progress of human being in scientific technology has greatly encouraged their belief in and worship of reason. Reason is incarnation of correctness and reliability, while the scientific technology which has obtained great development under guidance of scientific reason thinking necessarily is of correctness and reliability. It should be mentioned that, this kind of reason thinking has rarely had any rival until the middle of the Twentieth Century. Nevertheless, this kind of reason thinking has actually met with a refusal in the face of the history of the Twentieth Century. Racial segregation, all sorts of massacres, and especially outbreak of the two world wars which occurred in the Twentieth Century made people more doubtful how such an irrational outcome can happen when people used rationalized science and technology in an rational era. Until now when the history has developed to the current situation with moral controversy caused by ecological crisis, threat of nuclear war, chemical pollution, transgenosis pollution and human cloning, etc., suspect faced by legitimacy and reliability of enlightenment reason has reached a high tide.

Then, why a rational beginning gives rise to an irrational outcome? Generally speaking, there are three kinds of answers. (Xiao Ying, 2004) The first answer is that, according to Alexander, the representative of the neo-functionalism, there exists such an answer that some theorists don't believe it is the enlightenment reason that manufactures these disasters, but instead, it is "omnipresence" of irrationality that causes these disasters. According to him, "reality exists between the two extremes of perfection and disaster and all the greatest theorists in this century feel it a pity to come to realize omnipresence of irrationality. Their theory is to exhibit how irrationality functions in different fields and with different methods and how different types of results are generated." (Jeffery C. Alexander, 2003, 109) However, "a large majority of people still have not given up regarding science as a hope and have not regarded rationality as a kind of possibility... they resort to reason to manifest their standpoint and they also wish to find a more beautiful life means with their hard-won understanding. This kind of life will make people aware that they have no way to break away from feeling of irrationality and the need to convey meaning of life more specifically and with more expressions. However, by strengthening our rational understanding, there might have a kind of social life means which satisfies these needs with a more flexible method." (Jeffery C. Alexander, 2003, 109) That is to say, these theorists still have not given up their belief in the power of reason. And they believe that so long as the reason gets fully developed, it is totally possible for human being to break away from any disaster in the past and in the future.

The second answer originates from classification of Weber to rationality. According to Weber, rationality is absolutely not the unique means of people's life and behavior. At the same time, human being is necessarily a seiende with meaning and emotion. Thus, he classified rationality into instrumental rationality and value rationality. The crucial reason for occurrence of modernistic disasters lies in "rationalization of rationality towards irrational elements in the whole social life, which gives rise to disappearance of meaning space and emotional demand of human existence." (Xiao Ying, 2004)

The third answer was put forward by some postmodernists. These postmodernists directly pointed to enlightenment reason per se. They made an attack on reliability of rationality and on governance and control of rationality. Derrida started from the perspective of "post-structualism" to "construct" "Logos-centrism" in the tradition of western rationalism thought so as to realize proving unreliability of rationality. The US famous philosopher Rorty started from the perspective of the so-called "neo-pragmatism" to criticize the "image epistemology" in the tradition of western rationalism thought and subverted the traditional epistemology. Furthermore, Foucaul thought that it was existence of scientific rationality that made the superficially "human" but more precise and effective governance or control generated. As a result, the governance and control not only has not disappeared in the modern society, but becomes more precise and effective. In one word, according to postmodernists, rationality not only is lacking in reliability, but also is unlikely to realize its own promise of liberation, so it should be abandoned. (Xie Lizhong \& Ruan Xinbang, 2004)

All the above three answers to the question "why a rational beginning leads to an irrational result" have started from different perspectives. However, they have not been able to reveal the "constitutive paradox" (Xiao Ying, 2004) of the enlightenment reason per se. Ever since Descartes, the enlightenment reason has had such a deficiency that "For pursuit of definite knowledge, Descartes adopted a thoroughly doubtful means. Fundamentally speaking, this kind of rationality is a kind of doubtful rationality and the introspection method of rationality is also the method of self doubt essentially. If we carry forward introspection without limitation, then at which level introspection can be stopped and the foundation of certainty can be manifested?" (Xiao Ying, 2004) Therefrom, it can be seen that, "enlightenment reason is somewhat biased and any 'advanced' theory and scientific achievement it has produced has not got actual full proof." (Xiao Ying, 2004) Therefore, "In the process when people apply knowledge of introspection, the so-called necessity knowledge actually is nothing 
more than a kind of misunderstanding." (Anthony Giddens, 2000, 34) This indicates that the enlightenment rationality intends to obtain bankruptcy of knowledge with certainty through introspection.

\section{The environmental security concept to be held by the modern society}

To a large extent, the environmental issues caused by human activities are actually caused by rapid development of human scientific technology. On one hand, science and technology has brought prosperity to human kind, but on the other hand, it also has done harm to stability of the ecological system of the earth. The rational thinking which guides human activities is still enlightenment reason, which is a sort of instrumental rationality, and with development of science and technology of industrial revolution, this kind of instrumental rationality is continuously combined together with science and technology to form scientific rationality. "Dogmatism of scientific rationality changes the relationship between human being and the outside world to a purely instrumental relationship. Every tree and bush of the great nature is no longer vital body in the eyes of modern people and has nothing to do with existence of human being in terms of moral value, but is nothing more than some instrument or material for human being to use and to improve their material life." (Ruan Xinbang, 2004) As for the environmental issues caused by human activities, those people who hold a scientific thinking still believe that so long as they are able to develop more better and more mature technology, they can resolve the environmental issues fundamentally. Those who hold this viewpoint haven't come to realize the constitutive paradox of the enlightenment reason, instrumental rationality and even scientific rationality in their primary sense. It is exactly under domination of this kind of rational thinking that people go to an uncertain society at the time when they share material abundance. The environmental issues caused by human activities are absolutely not merely those phenomena within our vision. Behind the environmental issues hide the risks that we have not been able to predict so far. That is to say, there exists uncertainty. Human beings have pursuit in security and stability. In the traditional society, it was often that people turned to fall back on witchcraft, divination and even religious rites to pursue certainty and security. However, after the industrial revolution, "science itself became a kind of tradition - an established authority for people to search for resolutions for puzzles or problems." (Anthony Giddens, 2001, 108) "Although science has always been attempting to offer most reliable information about the world we have been longing for", (Anthony Giddens, 2000, 35) still there is no knowledge that is of total certainty. In the modern society, knowledge has the feature that it can be modified. One of the reasons for such a phenomenon is the constitutive paradox of the enlightenment reason per se.

When both science and rationality become the targets of suspect, then whether certainty still exists? In the modern society, development of science and technology has made people more and more unable to predict outcome of technology, according to understanding of Jonas, which means that the situation of "predicted knowledge" "lags behind knowledge of technology". The result is that human beings lose control over knowledge and technology and power of knowledge has posed austere threat to human beings. (Gu Zhonghua, $2001,78)$ This kind of situation makes the modern society enter step by step the so-called "risk society" propose by the Germany sociologist Urich Back. In his "Antidote", Back put forward strategies to strengthen security in a risk society, namely, "to enhance our sensitivity to any possible damage, break down monopoly of scientific experts on the definition of security and enhance standard of security, re-allocate burden of persuasion to make the decision makers hyalinized, so that when any damage occurs, there are people who take the responsibility." (Gu Zhonghua, 2001, 83) People's reaction to the current condition of environmental security includes the following three kinds of attitudes (Norman Myers, 2001, 247). One kind of attitude is an optimism attitude, which persists in scientific rationality and believes that so long as human beings can develop better and more mature technology, they can cope with any environmental issue that has been newly emerging, regardless of unpredictability of the environmental issues. And according to this kind of attitude, human beings could overcome threat in the past, and they are still able to resolve any environmental issue with their own rationality capacity in the future. According to the authors, this kind of optimism environmental security is quite similar to the aforementioned frog that "dies from peace and happiness", which falls within the scope of the so-called "those without a clear mind" (Wang Jin, 2000, 67) that was put forward by the famous France geoscientist C.J. Allegre. The second attitude is pessimism attitude, which holds the view that whatever people do, the result must be quite bad. Those who hold this viewpoint are not only demoralized, but are likely to have a kind of "existential anxiety" (Anthony Giddens, 1998, 39), namely, ontological insecurity. The third kind of attitude is the active aggressiveness attitude. Those who take this attitude believe that, although we encounter an environmental issue and there is great unpredictability and uncertainty, still we can take active actions to reduce any unfavorable influences and even overcome the environmental issue. The final kind of attitude is what we should take, namely, 'the real problem is not 'whether there will be one day when we are able to do it?', but 'why we are unable to do it immediately?"' (Norman Myers, 2001, 247) In the process of people's introspection 
on the environmental security, on one hand, people have to be compelled to take an action based on existence of actual environmental aggression and take part in the activities to maintain our rights of the environment. On the other hand, considering the possibility of unpredicted environmental aggression, people are urged to alter the existing action mode and employ another action means to satisfy their fundamental security in order to search for a new kind of security feeling and avoid any anxiety of "living in unpredictability".

\section{References}

Anthony Giddens. (1998). Modernity and Self-Identity, translated by Zhao, Xudong \& Fang, Wen. Joint Publishing Co.

Anthony Giddens. (1998). The constitution of society, translated by Li, Kang and Li, Meng, edited by Wang, Mingming. Joint Publishing Co.

Anthony Giddens. (2000). The Consequences of Modernity, translated by Tian, He. Yilin Publishing House.

Anthony Giddens. (2001). Run Away World, translated by Zhou, Hongyun. Jiangxi People's Publishing House, p.108.

Cai, Shouqiu. (2001). On Environmental Security. Journal of Safety and Environment, No. 5.

Gu, Zhonghua. (2001). The Second Modernity --- Way out for a Risk Society. Taipei: Juliu Publishing Company, p.78.

Jeffery C. Alexander. (2003). Fin de siecle social theory. Shanghai People's Publishing House.

Norman Myers. (2001). Safety Last, translated by Wang, Zhengping \& Jin, Zhongjun. Shanghai Yiwen Publishing House, p.247.

Ruan, Xinbang. (2004). Habermas's Comment on Modernity, In Xie, Lizhong \& Ruan, Xinbang. Modernity and Post-modernity Social Theory: Explanation and Comment. Peking University Press, p.235.

Wang, Jin. (2000). Notion and Values Seeking of Environmental Law-Study on the Objectives of Environmental Law. Law Press, p.67.

Xiao, Ying. (2004). Introspection and Self-reflection --- Study on "Reflexivity" in Sociology. Phd Thesis of Graduate School of Chinese Academy of Social Sciences in 2004.

Xie, Lizhong \& Ruan, Xinbang. (2004). Modernity and Post-modernity Social Theory: Explanation and Comment. Peking University Press, Introduction. 